Supporting Information

\title{
Novel Ene Trimerization of 1-Phenylcyclopropene
}

\author{
Gon-Ann Lee* and Chih-Yi Chang \\ Department of Chemistry, Fu Jen Catholic University, Hsinchuang, Taipei 24205, \\ Taiwan, Republic of China. \\ E-mail: chem1010@mails.fju.edu.tw
}

Table of Contents

1. ${ }^{1} \mathrm{H}$ and ${ }^{13} \mathrm{C}$ NMR spectra for compounds $2, \mathbf{3}, \mathbf{4}, \mathbf{6}, \mathbf{7}$, and $9 \ldots \ldots . . \mathrm{S} 2$ 

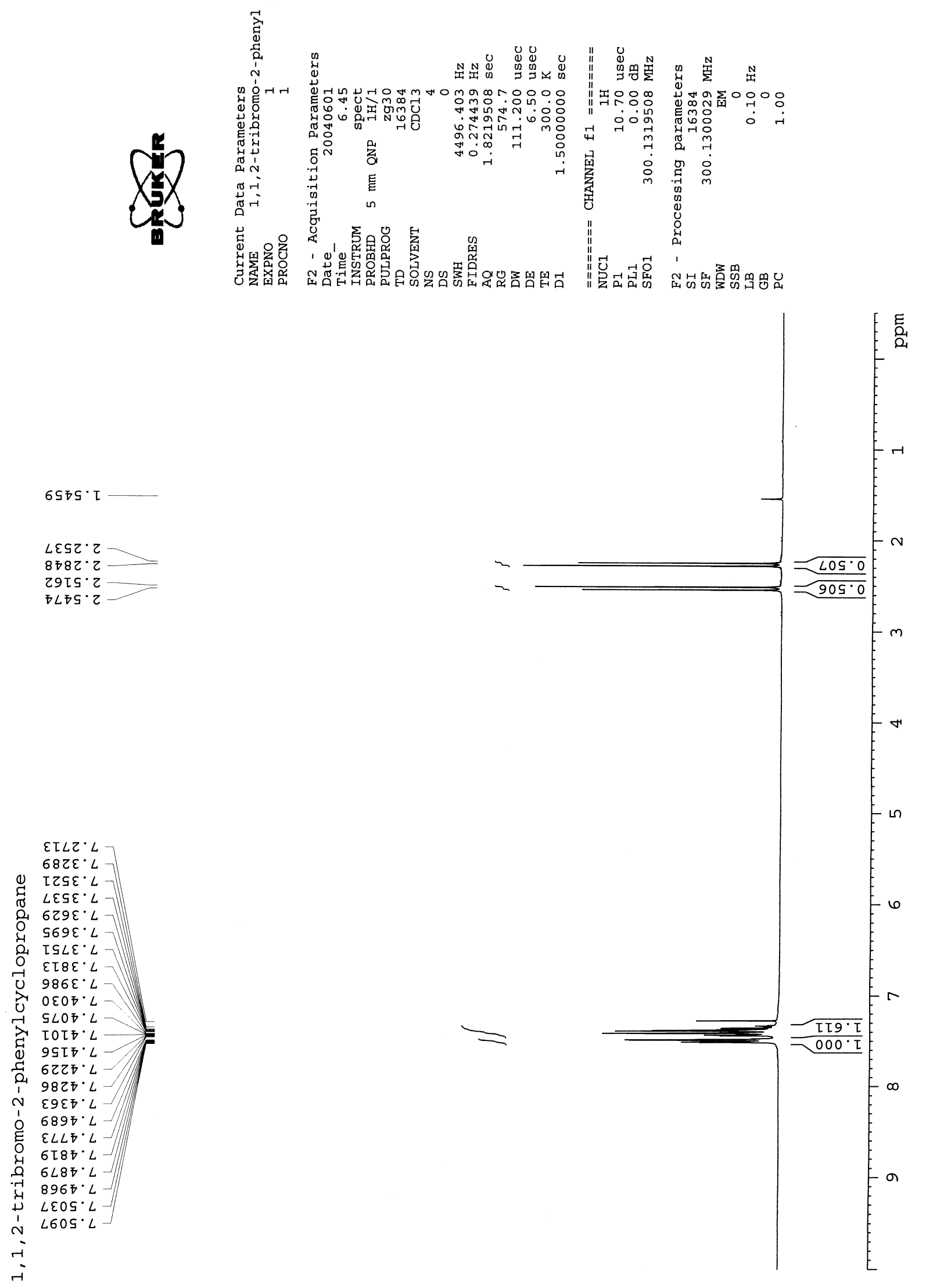

Figure 1. ${ }^{1} \mathrm{H}$ NMR spectrum of compound 2. 

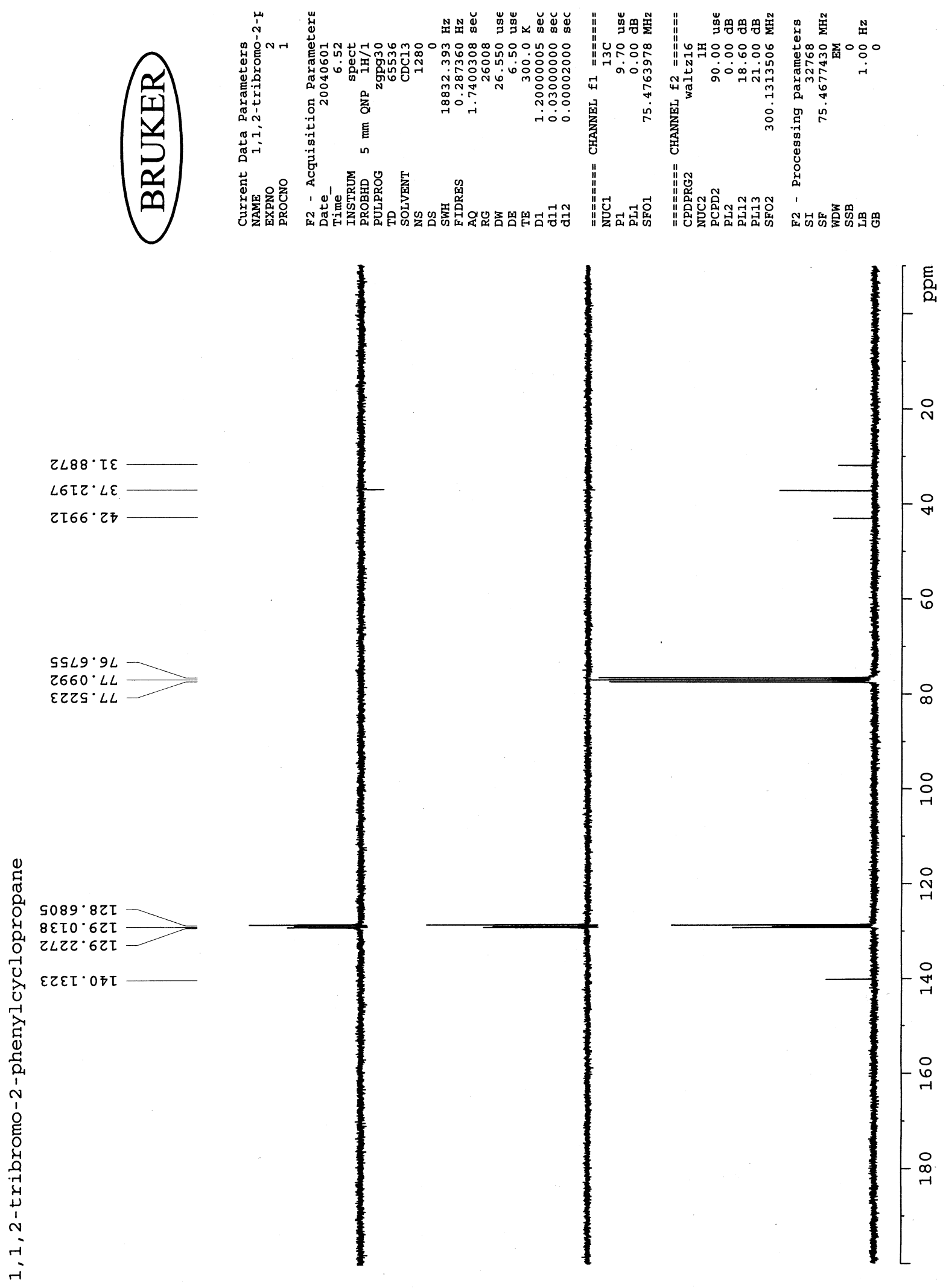

Figure 2. ${ }^{13} \mathrm{C}$ NMR spectra of compound 2 . 


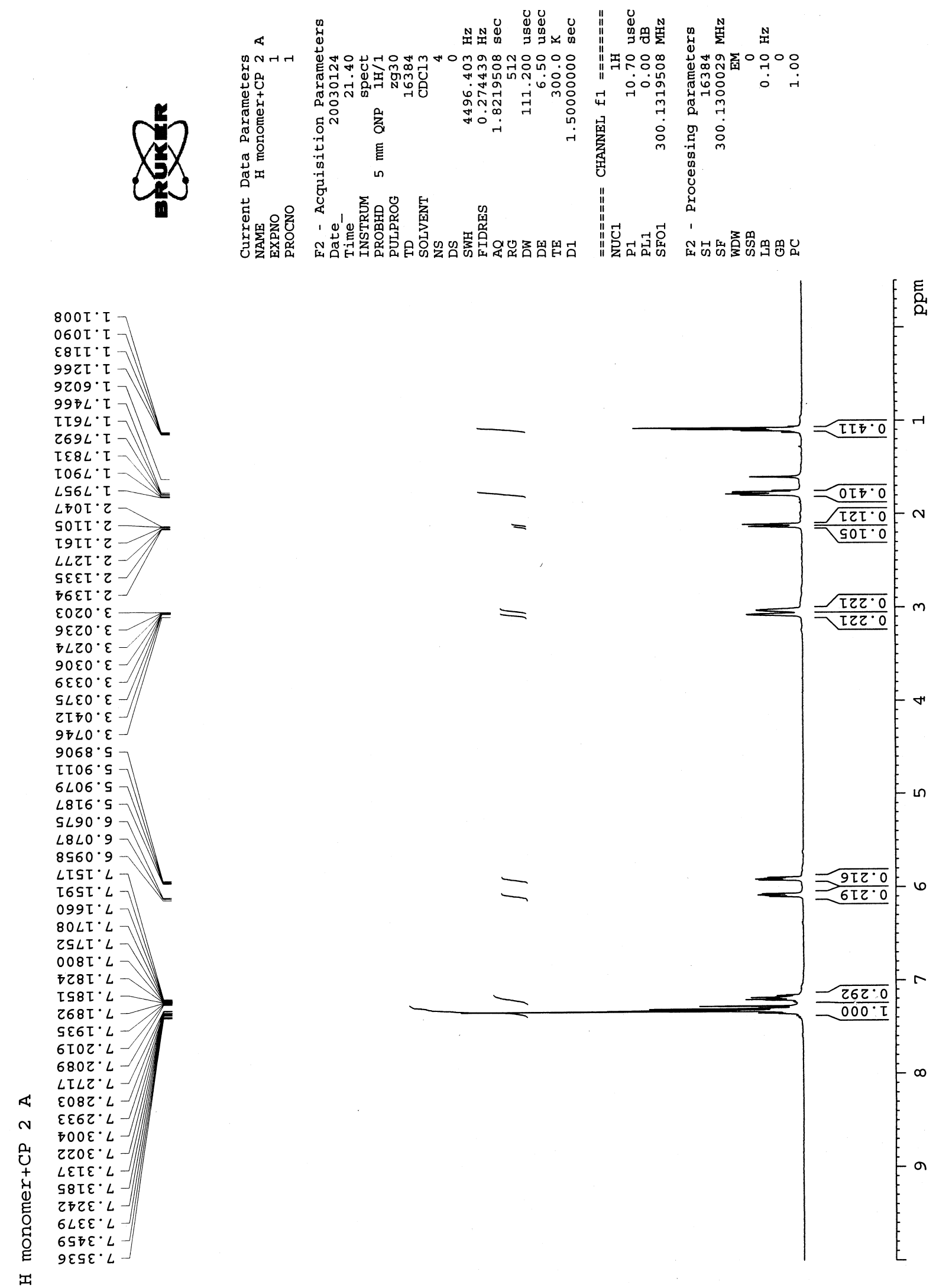

Figure 3. ${ }^{1} \mathrm{H}$ NMR spectrum of compound 3 . 


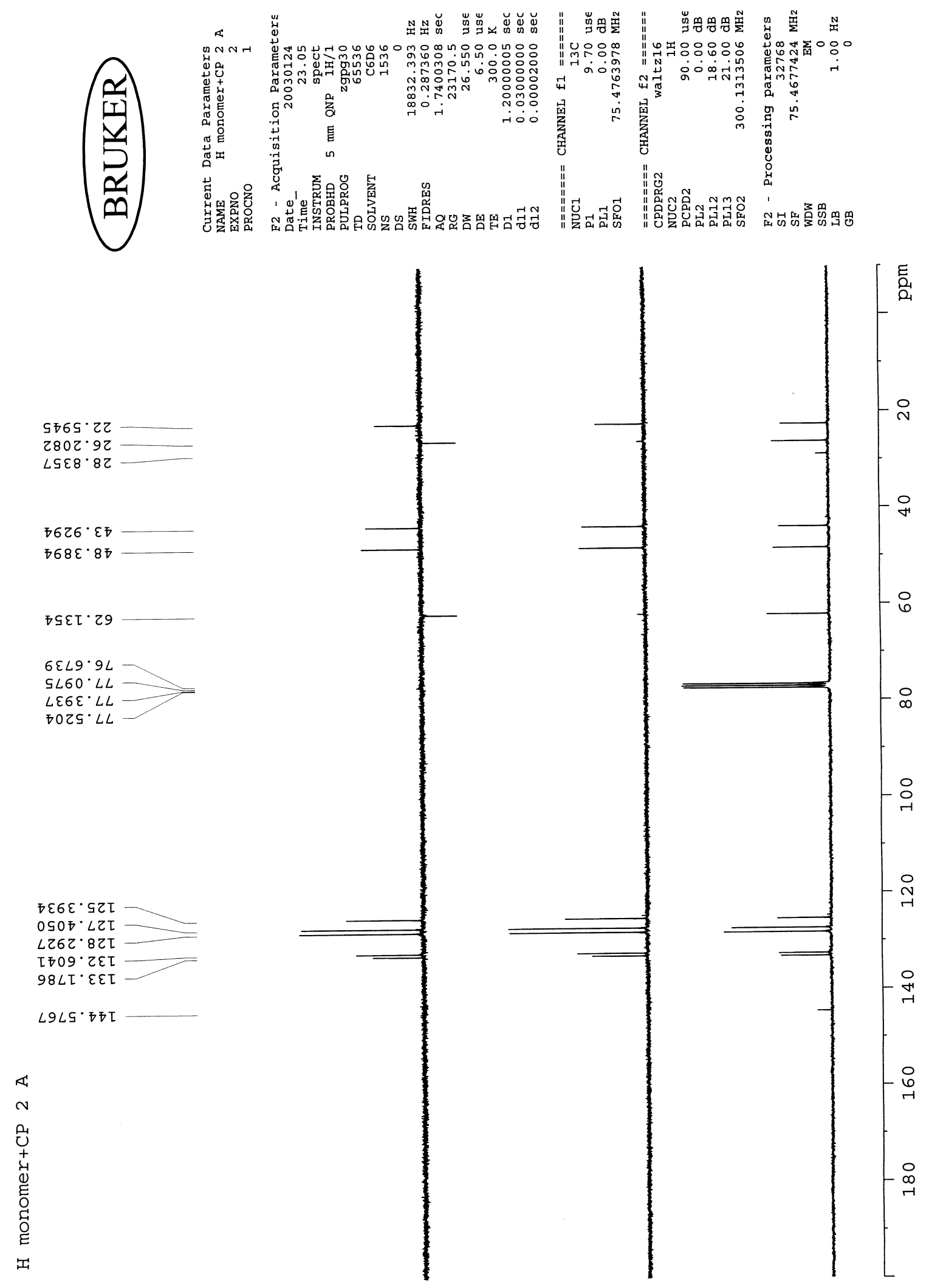

Figure 4. ${ }^{13} \mathrm{C}$ NMR spectra of compound 3 . 


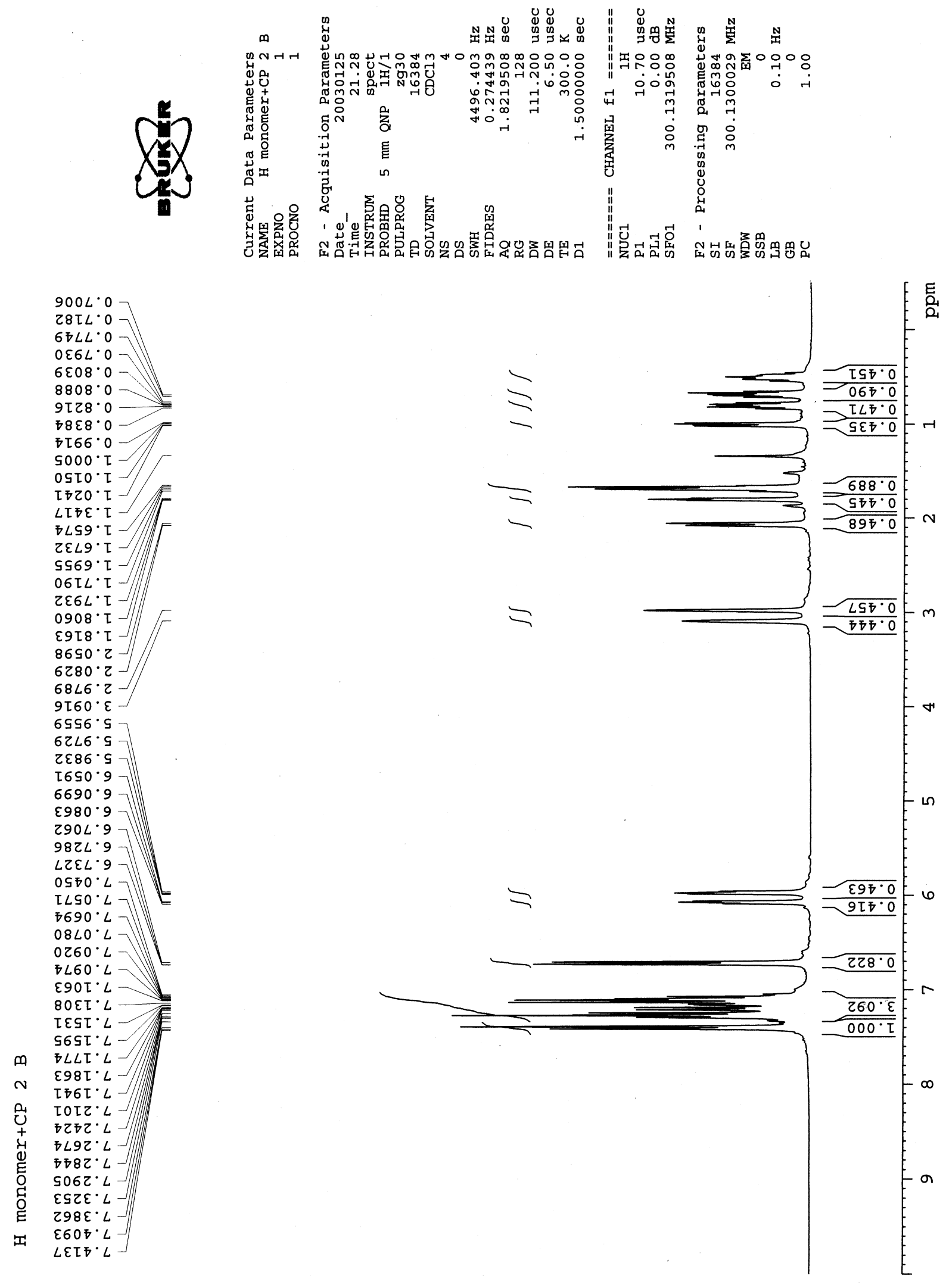

Figure 5. ${ }^{1} \mathrm{H}$ NMR spectrum of compound 4. 


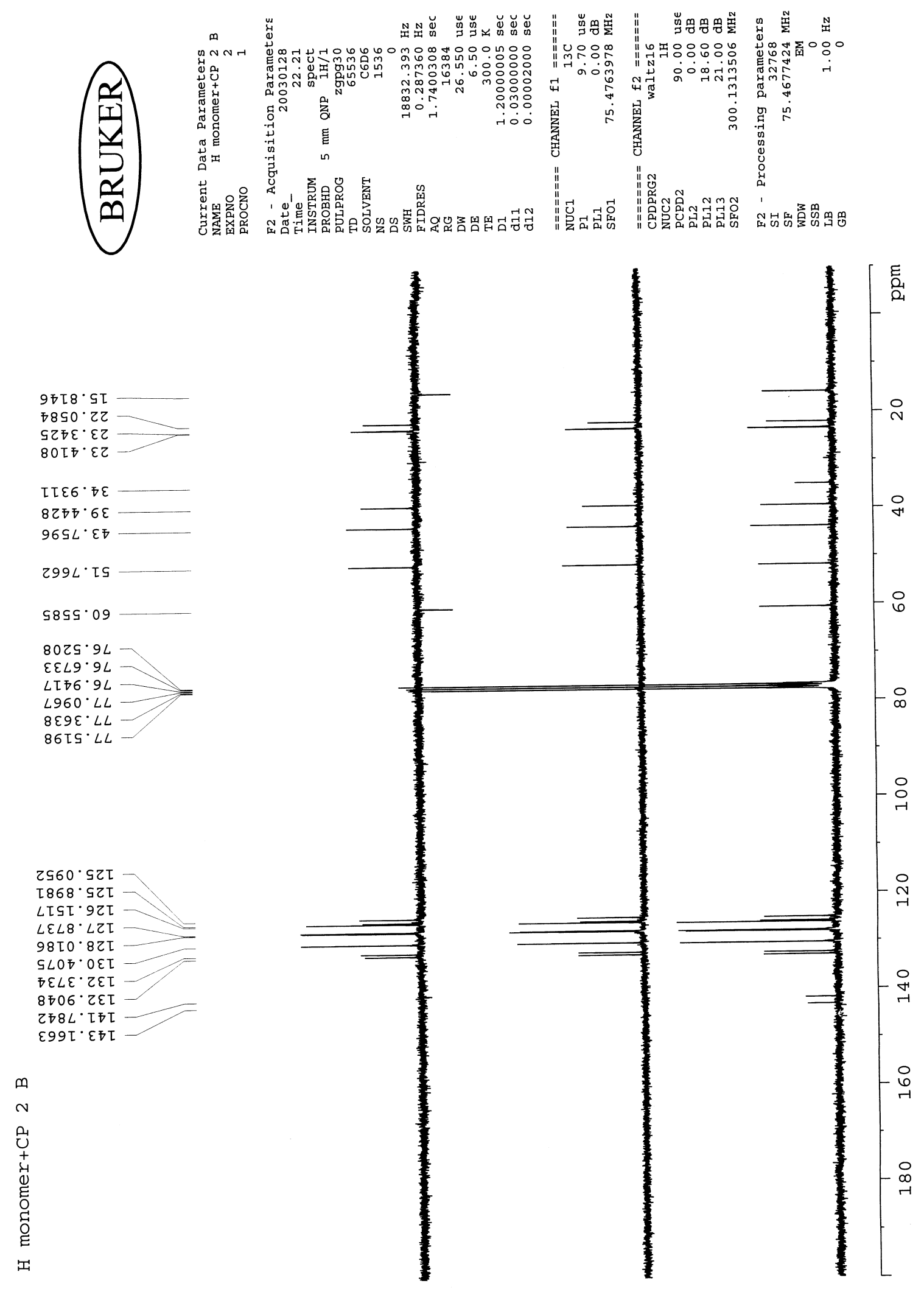

Figure 6. ${ }^{13} \mathrm{C}$ NMR spectra of compound 4 . 

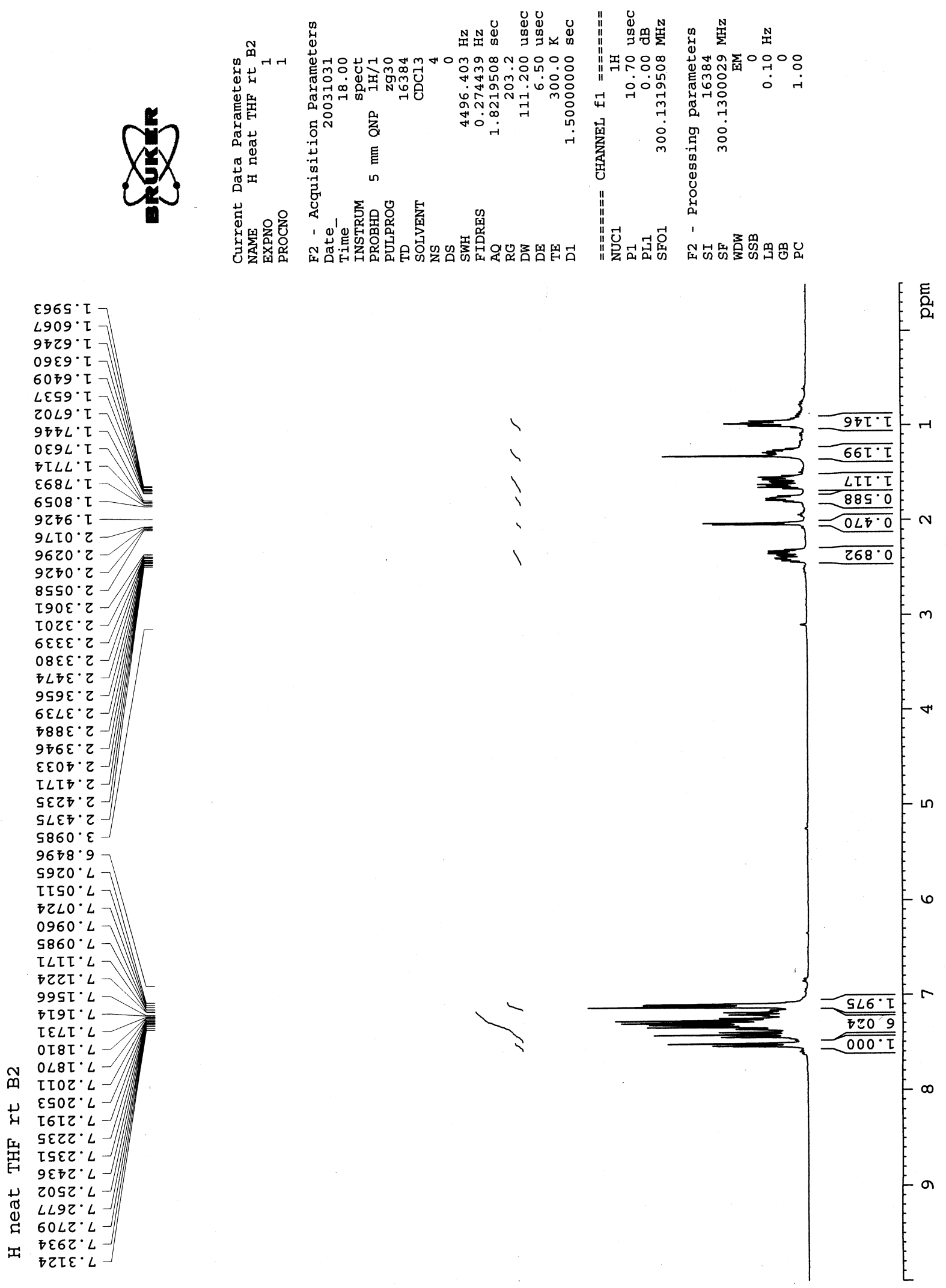

Figure 7. ${ }^{1} \mathrm{H}$ NMR spectrum of compound 6. 


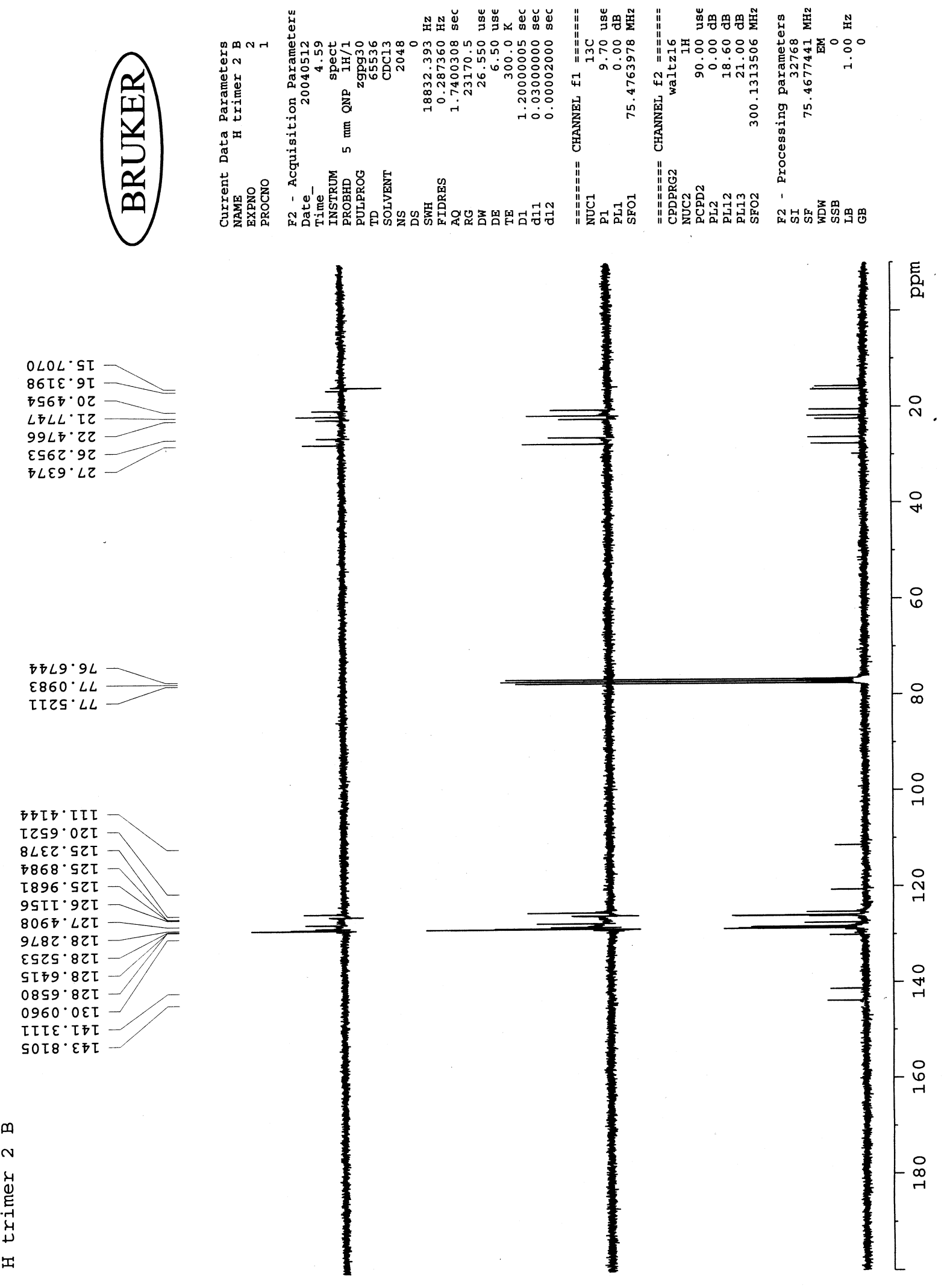

Figure 8. ${ }^{13} \mathrm{C}$ NMR spectra of compound 6 . 

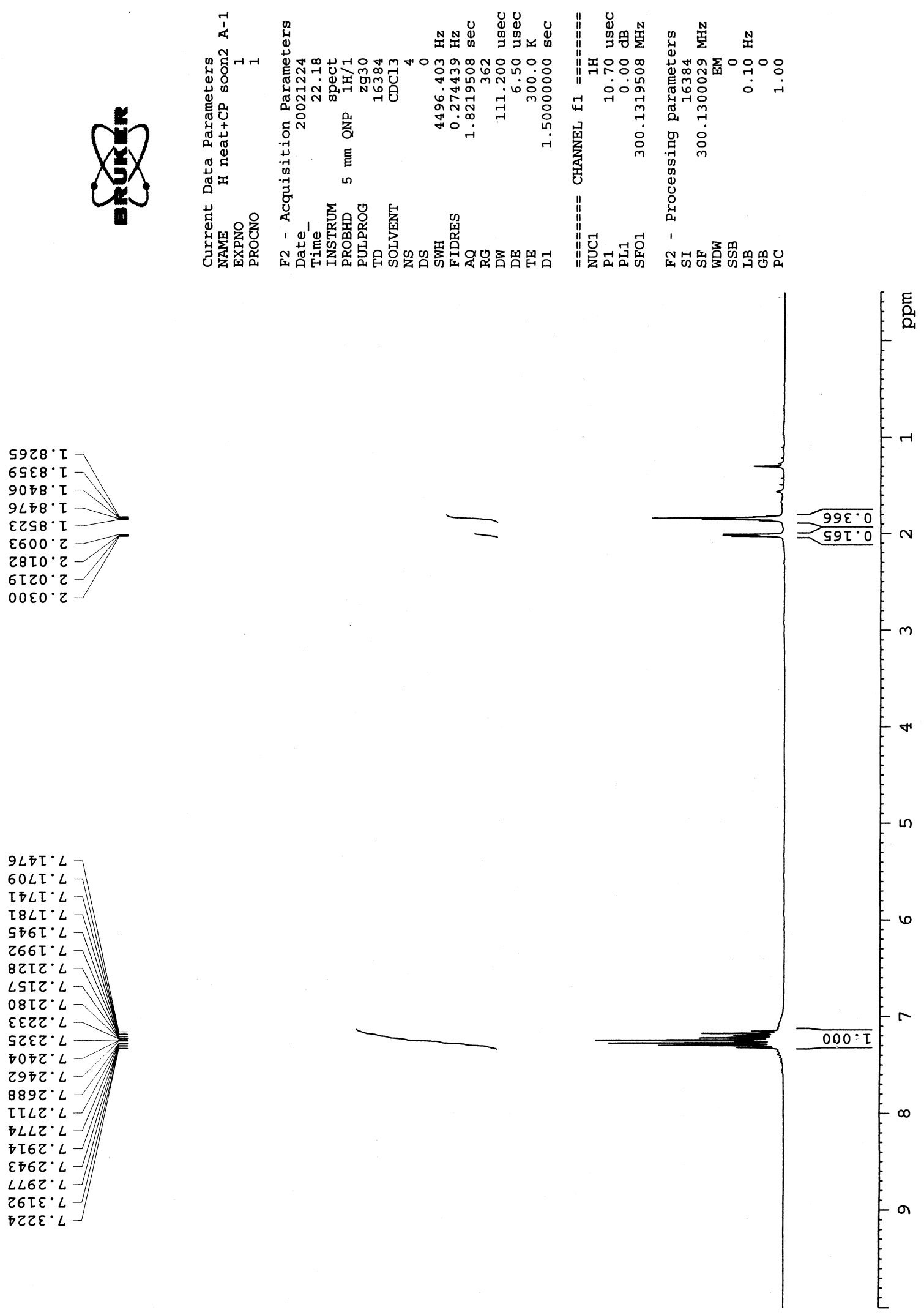

Figure 9. ${ }^{1} \mathrm{H}$ NMR spectrum of compound 7. 


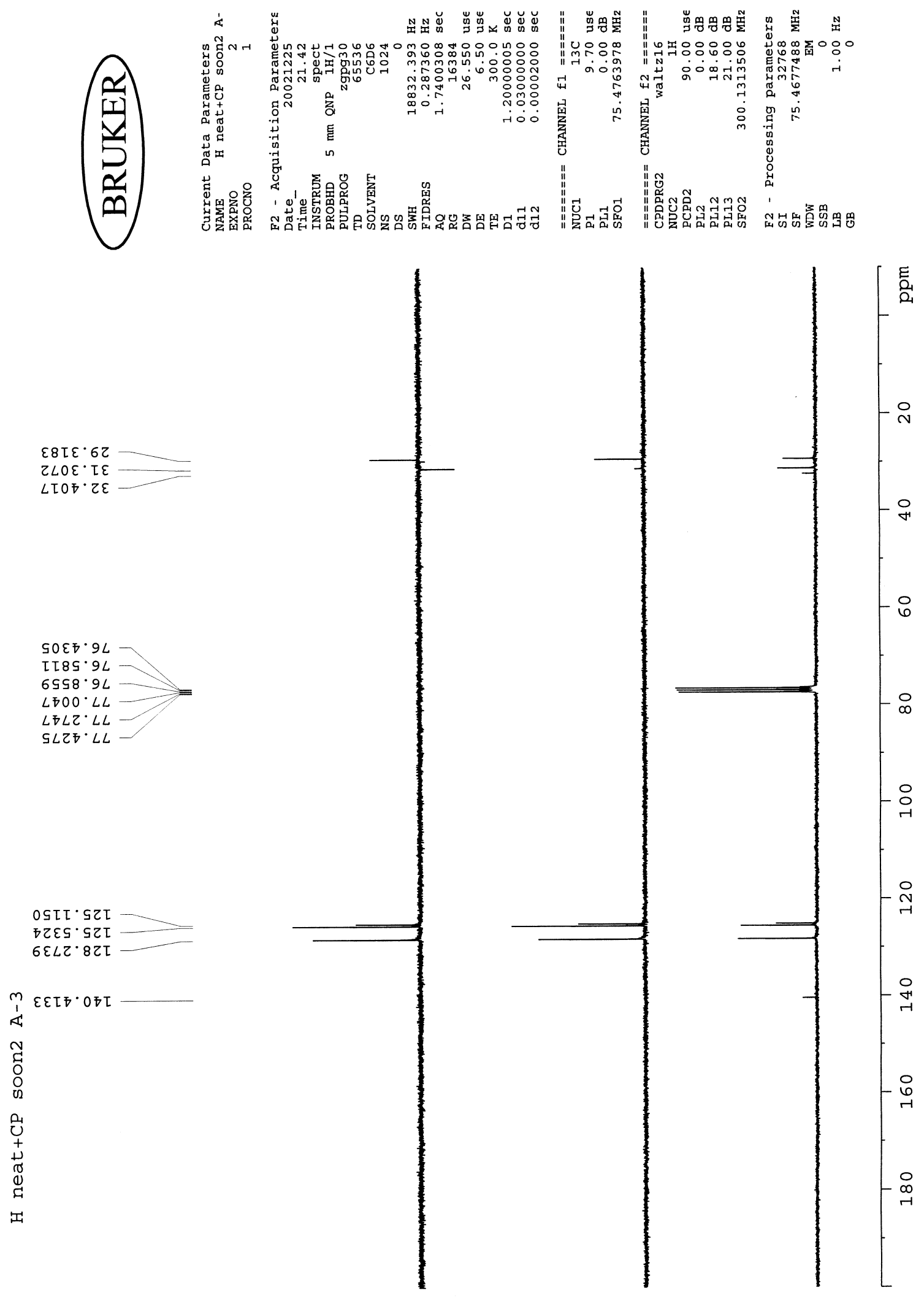

Figure 10. ${ }^{13} \mathrm{C}$ NMR spectra of compound 7. 

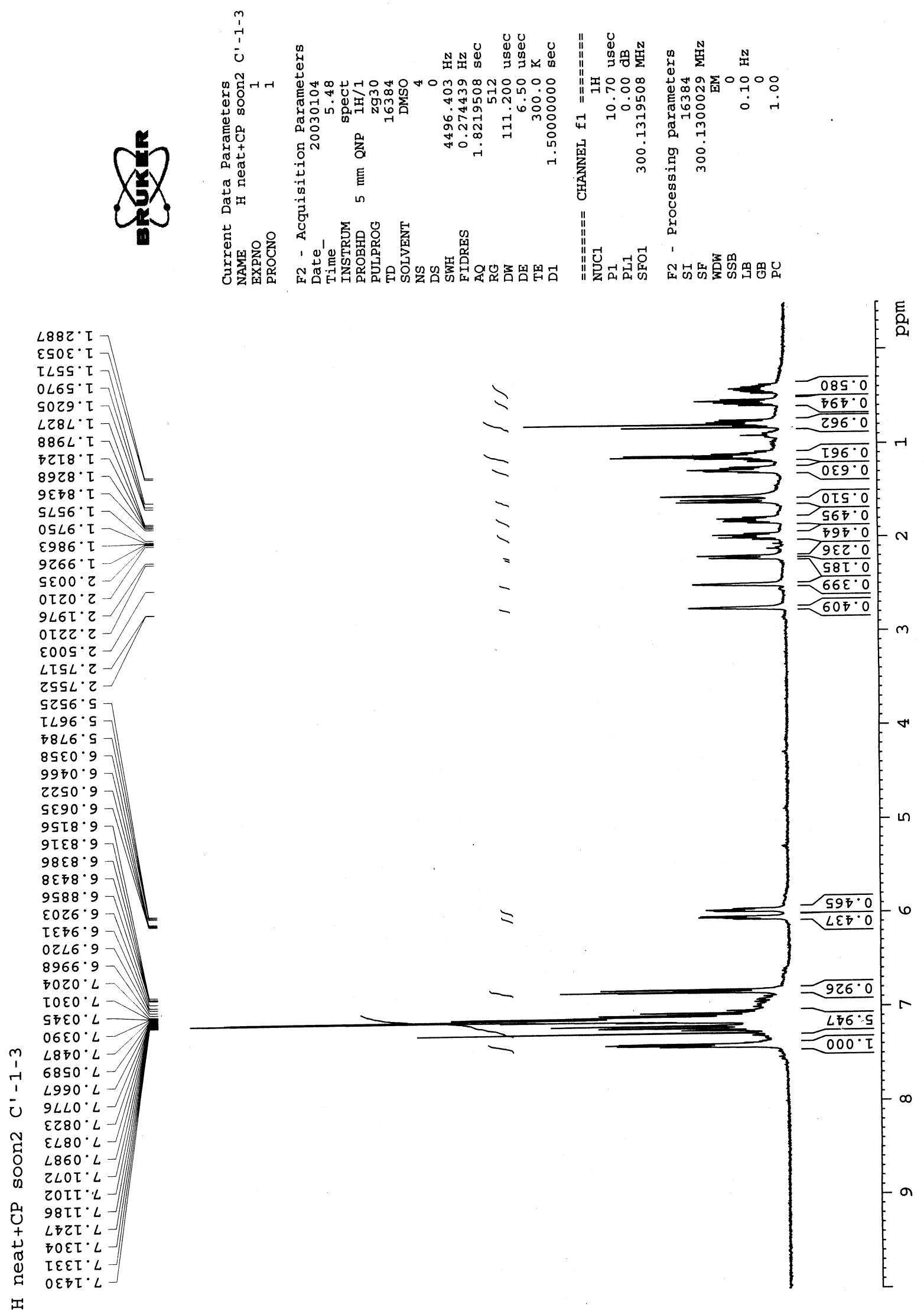

Figure 11. ${ }^{1} \mathrm{H}$ NMR spectrum of compound 9. 


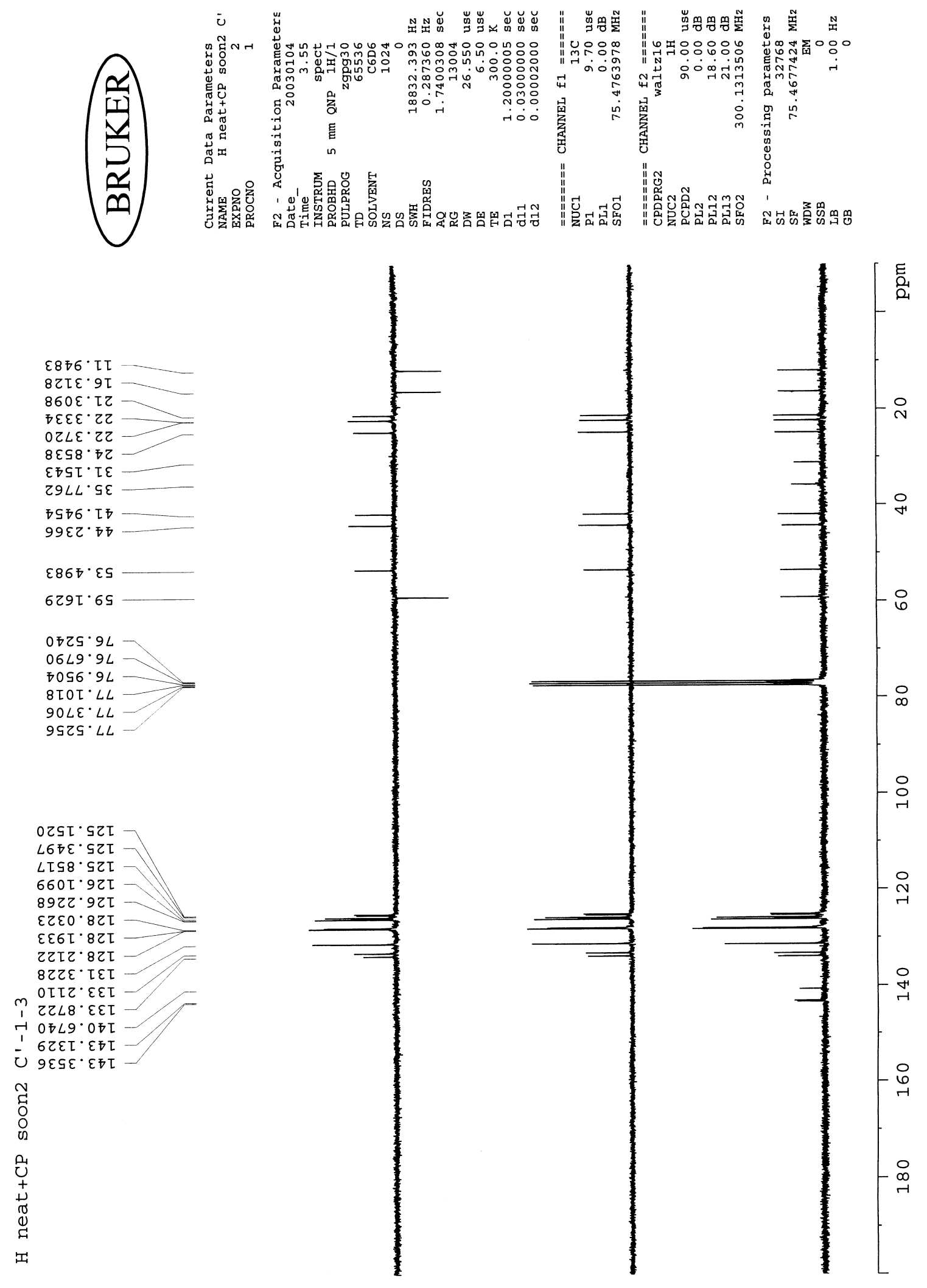

Figure 12. ${ }^{13} \mathrm{C}$ NMR spectra of compound 9. 